\& J. Edu. \& Sci., Vol. (24), No. (1) 2011 \&

\title{
The Effect of Hole Radius on The Properties of Large Pitch Photonic Crystal Fiber
}

\author{
Rasha Abdulaziz Faris \\ Abdulghafor Ibrahim Abdullah \\ Department of Physics / College of Education \\ University of Mosul
}

Received

01 / 06 / 2009
Accepted

$06 / 10 / 2009$

الخلاصة

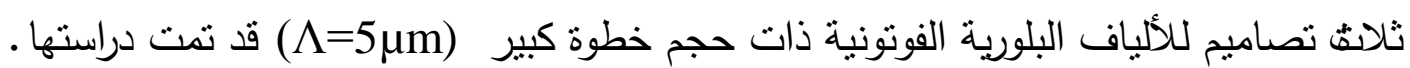


المعلمات لهذه التصاميم PCF1 و PCF2 و Pانت ثانتابته عدا نصف قطر الفجوة الهوائية والذي كانت قيمته 0.5، 0.8، 1.0 مايكرون على التوالي للألياف البلورية الفونونية قيد الدراسة .

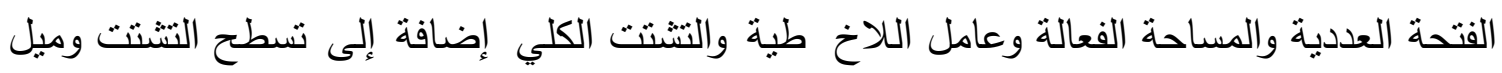
التتتت والطول الموجي عند التتشت الصفري للتصاميم الثلاث تم البحث فئه فيها.

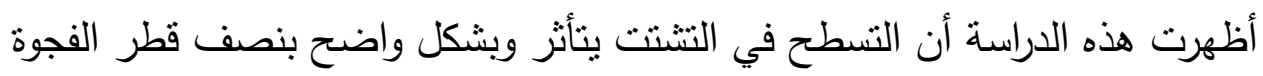

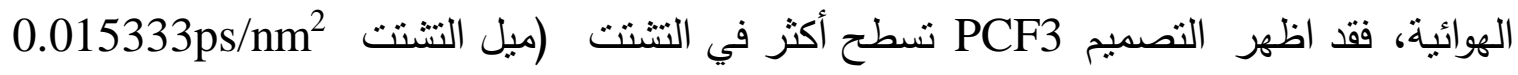

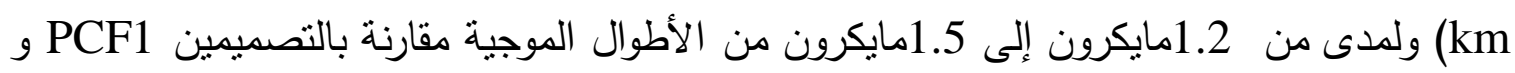
PCF2

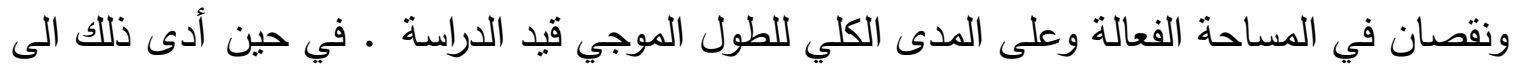

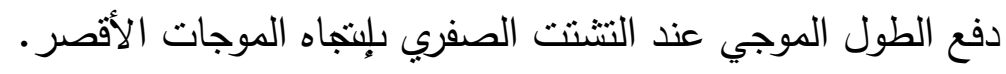

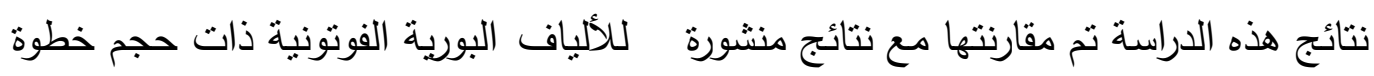

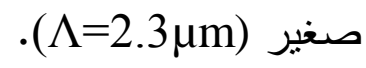

\section{Abstract}

Three proposals of large pitch $(\Lambda=5 \mu \mathrm{m})$ photonic crystal fibers (PCFs) are studied. The effect of air hole radius on the properties of the fundamental mode of these fibers are considered. All the parameters of the proposed structured were kept constant except the hole radius were varied $0.5,0.8$, and $1.0 \mu \mathrm{m}$ for the PCF1, PCF2 and PCF3 respectively. 
Numerical aperture, effective area, nonlinear coefficient, dispersion, flattened dispersion, dispersion slope and zero dispersion wavelength of the PCFs were all investigated.

This study shows that the dispersion profile was affected by the radius of the hole and PCF3 showed more flattened dispersion (dispersion slope of $0.015333 \mathrm{ps} / \mathrm{nm}^{2} . \mathrm{km}$ ), in range of $1.2 \sim 1.5 \mu \mathrm{m}$ of wavelength compared to PCF1 and PCF2 structures. On other hand, the increase of air hole radius increased the numerical aperture and decreased the effective area along the full range of wavelength, while zero dispersion point was shifted towards the shorter wavelength.

The calculated results were compared with other published work of small pitch $(\Lambda=2.3 \mu \mathrm{m})$ photonic crystal fiber.

\section{1- Introduction}

Photonic crystal fibers (PCFs), also called holey fiber (HF) or microstructured optical fibers (MOFs), constitute a new class of photonic crystal waveguides were proposed in 1992. The first working example of PCF was made by Knight et al in 1996 [1]. In comparison with conventional optical fibers, guided propagation of the electromagnetic field in the PCFs is achieved by the introduction of defects. These defects form a periodic pattern of air holes in regular triangular lattice, around a silica core, and acts as a cladding of the PCF[2]. The effective refractive index is considered as an average over the solid silica and the air holes it contains. Thus the cladding region has a lower average refractive index than the core and confines light by total internal reflection like standard fibers, as shown in Fig.(1).

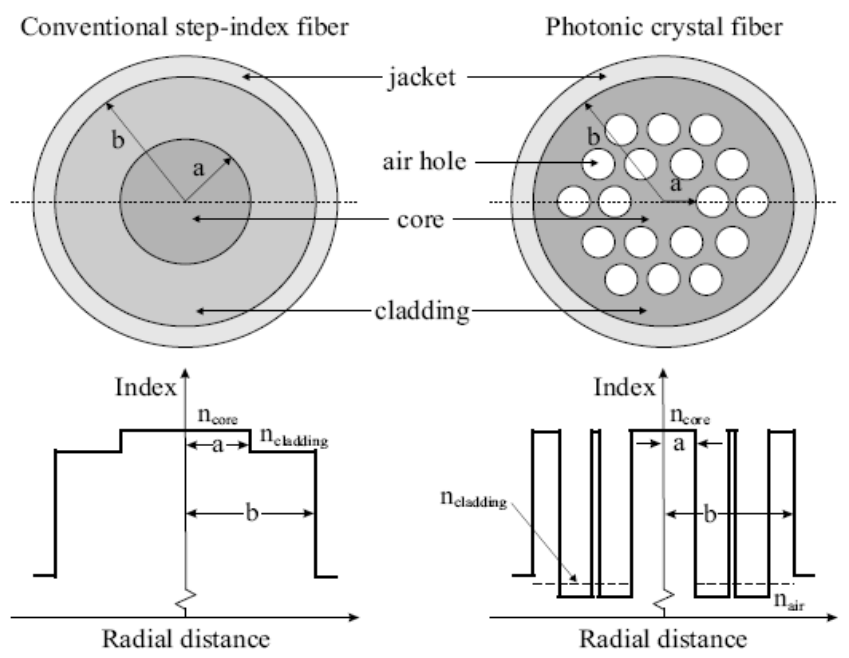

Fig. 1: Schematic illustration of the cross section and refractive index profile for a step index optical fiber and index guiding photonic crystal fiber [2]. 
The basic structure of the PCFs is shown in Fig(2), the small circles of diameter a represents air holes that run the length of the fiber, and $\boldsymbol{\Lambda}$ is the distance between two centers of holes, and called the pitch size. The core, which may be either solid or air, depending on the design and intended purpose. In either case, the region represents a defect in the structural pattern. If solid, the core radius extends to the inner edge of the first ring of holes that means the air holes are typically arranged in a triangular lattice. The silica core guiding the light is formed by the missing air hole. The guidance mechanism depends on the nature of the defects and the air hole arrangement [3].

According to the guidance mechanism, PCFs can be divided in to two categories:[3] Total Internal Reflection(TIR), where air holes surround a high index solid core, and Photonic Band Gap (PBG), where the light is confined to a central air hole [4].

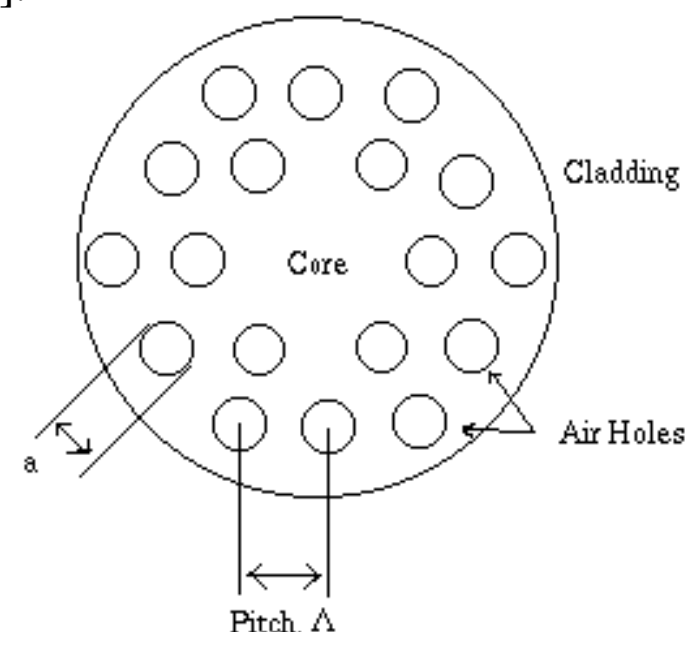

Fig. 2: Schematic representation of a PCFs.

PCFs have many remarkable properties such as large and adjustable dispersion and nonlinearity [5], single mode and the nearly-zero dispersion (NZD)[6], flattened dispersion or endless single mode operation over a wide range of wavelength[7,8], that means, achieving good control of dispersion.

In practical applications, the numerical aperture, effective area, nonlinear coefficient, dispersion, flattened dispersion, dispersion slope and zero dispersion wavelength parameters are needed for some particular applications. Such characteristics, under the effect of the hole radius and constant large pitch size, will be the aim of this study.

This paper is organized as follows: in section 2, theoretical part, the relation between the effective area $A_{\text {eff }}$ and the numerical aperture NA of the PCFs. The relations of the nonlinear coefficient $\gamma$, dispersion $\mathrm{D}(\lambda)$ and 
dispersion slope $\mathrm{dD}(\lambda) / \mathrm{d} \lambda$ of the proposals PCFs are also present. In section 3 the results and discussion for the PCFs under study, in addition to the comparison between the present results with other published work of small pitch PCFs were reported. Finally conclusion and future work are given in section 4.

\section{2- Theoretical Part}

The theoretical relations and their definitions which are used in this work are described as follows.

\subsection{V-Number (Normalized Frequency)}

The $\mathrm{V}$ number or the normalized frequency determines the number of confined modes to be exist in the core. The equation used in conventional fiber to calculate the V-number is modified by Mortensen et al [10] to get

$$
\mathrm{V}=2 \pi \frac{\Lambda}{\lambda} \sqrt{\mathrm{n}_{\mathrm{c}}^{2}(\lambda)-\mathrm{n}_{\mathrm{eff}}^{2}(\lambda)}
$$

here $\Lambda, n_{c}, n_{\text {eff }}$ are the pitch size, refractive index of the core and the effective refractive index of the air hole array respectively [2,11,12]. V-value in PCFs stays at fixed value even if the wavelength shortened, because of the strong wavelength dependence of the $n_{\text {eff. }}$. The special aspect of PCFs is that with increasing wavelength, the effective cladding index is decreases, this serving the offset the increase in V-value. This means PCFs can offer single mode operation from the visible to infrared region. This characteristics is not possible with conventional single mode fiber. Fig. 3 shows the calculated V number as a function of wavelength for a large pitch PCF $(\Lambda=5 \mu \mathrm{m})$ and different air hole radius [13]. The figure shows also the dashed line indicates the single mode cutoff value of $(\mathrm{V}=2.405)$.

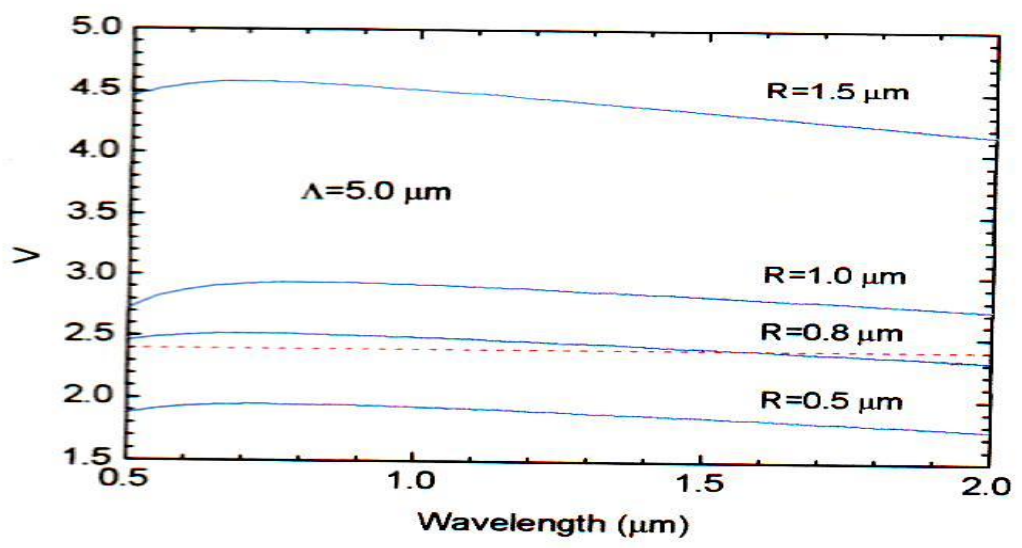


Fig. 3: V-number vs. wavelength for different air hole radii of a PCFs [13].

\subsection{Numerical Aperture NA}

It is an important characteristics of an optical fiber showing its gathering ability of the incident light over wide range of angles, for PCFs the NA is given as the following [2]

$$
\mathrm{NA}=\sin \theta=\sqrt{\mathrm{n}_{\mathrm{c}}^{2}(\lambda)-\mathrm{n}_{\text {eff }}^{2}(\lambda)}
$$

Where $\theta$ is the half divergence angle, $\mathrm{n}_{\mathrm{c}}(\lambda)$ is the refractive index of the core, and $\mathrm{n}_{\text {eff }}(\lambda)$ is the effective refractive index of the surrounding. NA is usually relate to the effective area $A_{e f f}$; for Gaussian field of width $w$, or spot size, one has the standard approximate expression[10]:

$$
\tan \theta=\lambda / \pi \mathrm{w}
$$

For the half divergence angle $\theta$ of the light radiated from the end-facet of the fiber. The relation of the NA in terms of $A_{\text {eff }}$ which was used in a study of the numerical aperture of PCFs by Mortensen[9] and Mortensen et al [10] is given as the following:

$$
A_{\text {eff }}=\frac{\lambda^{2}}{\pi}\left(\frac{1}{\mathrm{NA}^{2}}-1\right)
$$

The effective area is a quantity of a great importance because it is a measure of nonlinearities, and can be used to enhance or prevent the nonlinear effect, depending on the value of $A_{\text {eff. }}$.

In case of $w>\lambda$, Mortensen et al [10] showed that :

$$
A_{\text {eff }}=\pi w^{2}
$$

\subsection{Nonlinear Effect in PCFs and Nonlinear coefficient $\gamma$}

Knowledge of $A_{\text {eff }}$ is an important starting point to understand of nonlinear phenomena. The high index contrast between silica and air holes, the PCF technology offers the possibility of much tighter mode confinement and therefore a lower effective area compared to standard fiber[8].

One can say, that the different nonlinear effects in fiber can be either useful or undesirable depending on the application [3]. In modern communication systems which involves high power level and employ optical amplifiers, the use of nonlinear effect is extremely important.

The non-linear coefficient (NLC) $\gamma$ in terms of $A_{\text {eff }}$ is given by $[9,12,14]$

$$
\gamma=2 \pi \frac{\mathrm{n}_{2}}{\lambda} A_{\text {eff }}
$$

where $\mathrm{n}_{2}$ is nonlinear - index coefficient in the nonlinear part of the refractive index of silica fiber and equal to $2.5 \times 10^{-20} \mathrm{~m}^{2} \mathrm{~W}^{-1}$. 


$$
D(\lambda)=-\frac{\lambda}{c} \frac{d^{2} R n_{e f f}}{d \lambda^{2}}
$$

\subsection{Dispersion $D(\lambda)$ and Dispersion Slope $\operatorname{dD}(\lambda) / \mathrm{d} \lambda$ in PCFs}

The chromatic dispersion $\mathrm{D}(\lambda)$ of a PCFs is calculated from the real part of the $n_{\text {eff }}$ as a function of the wavelength using:[12]

where $\mathrm{c}$ is the velocity of the light in vacuum and $\mathrm{R}$ stands for the real part of the effective index. According to Eq.(7), the chromatic dispersion is calculated. While the derivative of the dispersion with respect to wavelength gives the dispersion slope and is expressed in units of the $\mathrm{ps} / \mathrm{nm}^{2} . \mathrm{km}$. from the second derivative of the effective index with respect to wavelength. Dispersion slope is often specified at selected wavelength along with $D(\lambda)$ in fiber and can be used to measure the flattened of the dispersionprofile for any PCFs structures[3].

$$
\frac{\mathrm{dD}(\lambda)}{\mathrm{d} \lambda}=-\frac{1}{c}\left(\frac{d^{2} R n_{\text {eff }}}{d \lambda^{2}}+\lambda \frac{d^{3} R n_{\text {eff }}}{d \lambda^{3}}\right)
$$

\section{3- Results and Discussion}

The published data of Z. Zhu and T. G. Brown [13] have been implemented in our calculations for total dispersion and other properties of PCFs for the fundamental mode. The effective index of different PCFs obtained by [13] are based on full vectorial method. Such a method is simple and efficient approach, which overcomes the general limitations of the plane wave expansion.

Three PCFs of same pitch size $(\Lambda=5 \mu \mathrm{m})$ and different hole radius ( $\mathrm{r}=$ $0.5 \mu \mathrm{m}$ for PCF1, $\mathrm{r}=0.8 \mu \mathrm{m}$ for PCF2, $\mathrm{r}=1.0 \mu \mathrm{m}$ for PCF3), without missing hole in the center of the core, were considered. These fibers can be single mode over very large spectral range $(0.5 \mu \mathrm{m}$ to $2.0 \mu \mathrm{m})$ as shown in Fig.(3). The material dispersion of silica is considered in the calculation [13], using the index of refraction of silica which is determined according to the Sellmeier equation [14].

\section{3-1 Numerical Aperture NA $(\lambda)$}

Fig. (4) shows the influence of the air hole radius on the numerical aperture. The results show that, using Eq. (2), by increasing the wavelength, the numerical aperture increased, one can say by adjusting the air hole radius, a high freedom in designing a fiber with a certain NA at a desired wavelength [10]. PCF3 shows high NA comparing with other PCF1 and PCF2 at the communications window. The large NA make the coupling between different PCFs easy and allowing very fast beams to propagate down the fiber. Such a 
property may not be possible in conventional single mode fiber due to small difference between the core and the clad index of refraction.

\section{3-2 Dispersion $D(\lambda), \lambda$ zD , and Dispersion Slope $\operatorname{dD}(\lambda) / \mathrm{d} \lambda$}

Chromatic dispersion in single mode fiber cause light pulses to spread, limiting the data transmission rate and length of optical fiber link. To overcome these limits, manipulating a hole radius is used to suppress the dispersion and obtaining negative dispersion [3].

The dispersion for different structures of PCFs (different air hole radius) were calculated as a function of wavelength, using the definition in Eq.(7), is illustrated in Fig.(5-a). The figure depicts that one can design PCFs by choosing appropriate hole radius to obtain a desired dispersion profile. It is very clear that the dispersion profile was affected by the hole radius and PCF3 exhibit near zero and flattened dispersion in a range 1.2 to $1.5 \mu \mathrm{m}$ of wavelength. While PCF1 gave small negative dispersion and flattened dispersion which was extended to a longer wavelength. The figure shows also that the continuous increment of the air hole radius pushed the $\lambda$ ZD point towards the shorter wavelength as shown in Fig.(5-b). This results is agree with other published work $[15,16]$. On other hand all the structures exhibits anomalous dispersion $\sim 100 \mathrm{ps} /(\mathrm{nm} . \mathrm{km})$ at $\lambda=0.8 \mu \mathrm{m}<\lambda_{\mathrm{ZD}}$ of Ti-Za laser, and the fiber remain single mode. The large manipulation in the design of the crystal fiber air hole radius provides further tuning of dispersion profile.

The calculated dispersion and dispersion slope using Eq.(7) and Eq.(8) respectively shows that $\mathrm{PCF} 3$ gives zero dispersion a smaller dispersion slope $\left(0.015333 \mathrm{ps} / \mathrm{nm}^{2} . \mathrm{km}\right)$ at $1.35 \mu \mathrm{m}$ communication wavelength, which confine that PCF3 has a flattened dispersion comparing with $0.090666 \mathrm{ps} / \mathrm{nm}^{2} . \mathrm{km}$ for PCF2 and $0.149583 \mathrm{ps} / \mathrm{nm}^{2} . \mathrm{km}$ for PCF1 at the same communication wavelength. Table 1, shows the dispersion slope for the PCFs under study at the communication wavelengths.

\section{3-3 Effective Area Aeff $(\lambda)$ and Nonlinear Coefficient $\gamma(\lambda)$}

In practical applications the zero or near zero dispersion characteristics flattened or ultra flattened dispersion may not be enough for justifying the usefulness of the PCFs, effective area (using Eq.4) and NLC (using Eq.6) which are strongly related to each other are another parameters may be needed for linear and nonlinear applications.

We have shown already that the proposed different PCFs are exhibiting zero dispersion characteristics in different wavelengths, see Fig.(5-A). The results of this work show that the proposed structure PCF1 of $\mathrm{r}=0.5 \mu \mathrm{m}$ had also larger effective area (Fig. 6) and smaller NLC (Fig.7) at all the spectrum $0.5 \mu \mathrm{m}$ to $2.0 \mu \mathrm{m}$. While NLC of the PCF3 (at $1.3 \mu \mathrm{m}$ ) was $54 \mathrm{Km}^{-1} \mathrm{~W}^{-1}$, 
which is about 10 times more than that of PCF2 $\left(5.5 \mathrm{Km}^{-1} \mathrm{~W}^{-1}\right)$ and 13 times more than that of PCF1 $\left(4.0 \mathrm{Km}^{-1} \mathrm{~W}^{-1}\right)$, PCF3 gives smaller effective area and larger nonlinear coefficient at all the spectrum of the study. The last structure can be designed specifically for use in supercontinuum generation (SCG) which is suitable for application in dense wavelength division multiplexing DWDM optical network and optical coherence tomography OCT, where high effective nonlinear are required [17,18].

PCF3 with such properties in addition with calculated $\mathrm{NA}(\lambda) \sim 0.153$ has been experimentally verified to result in high coupling efficiencies between single mode fiber and nonlinear PCF of small effective area [19].

\subsection{Comparison between Small pitch size PCFs and Large pitch size PCFs}

We compared the results of this work (calculated) as a large pitch PCFs $(\Lambda=5 \mu \mathrm{m})$ with other published work [20] for small pitch PCF $(\Lambda=2.3 \mu \mathrm{m})$. The aim of this comparison is to show, how the properties of the proposed PCFs are influenced by the size of the pitch size. (see table $1 \& 2$ ).

Table 1: Dispersion Slope for the proposed structures at the communication windows.

\begin{tabular}{|c|c|c|c|}
\hline \multirow{2}{*}{$\begin{array}{c}\text { Communication } \\
\text { Wavelength ( } \boldsymbol{\mu m})\end{array}$} & \multicolumn{3}{|c|}{ Dispersion Slope Ps/nm ${ }^{2} / \mathbf{k m}$} \\
\cline { 2 - 4 } & PCF1 & PCF2 & PCF3 \\
\hline 1.3 & 0.090666 & -0.149583 & -0.015333 \\
\hline 1.5 & -0.896234 & 0.180417 & 0.134667 \\
\hline
\end{tabular}

Table 2: Summary of the results.

\begin{tabular}{|c|c|c|c|c|c|c|c|}
\hline Parameters & calculated & $\begin{array}{l}\text { Published } \\
\text { [20 ] }\end{array}$ & calculated & $\begin{array}{l}\text { Published } \\
\text { [20 ] }\end{array}$ & calculated & $\begin{array}{c}\text { Published } \\
{[20]}\end{array}$ & units \\
\hline & \multicolumn{2}{|l|}{ P C F 1} & \multicolumn{2}{|l|}{ P C F 2} & \multicolumn{2}{|l|}{ P C F 3} & \\
\hline \multicolumn{8}{|l|}{$\frac{\text { Wavelength }}{0.8 \mu \mathrm{m}}$} \\
\hline NA & 0.049 & 0.07 & 0.065 & 0.15 & 0.12 & $\begin{array}{c}\begin{array}{c}\text { Not } \\
\text { available }\end{array} \\
\end{array}$ & Unit less \\
\hline $\mathrm{A}_{\text {eff }}$ & 84 & 30 & 50 & 8 & 37 & $\begin{array}{c}\text { Not } \\
\text { available }\end{array}$ & $\left(\mu \mathrm{m}^{2}\right)$ \\
\hline NLC & 5 & 6 & 7 & 19 & 54 & $\begin{array}{c}\text { Not } \\
\text { available }\end{array}$ & $\mathbf{K m}^{-1} \mathbf{W}^{-1}$ \\
\hline $\mathrm{D}(\lambda)$ & -100 & -100 & -95 & -110 & -90 & $\begin{array}{c}\text { Not } \\
\text { available }\end{array}$ & Ps/nm.km \\
\hline
\end{tabular}


Rasha Abdulaziz Faris \& Abdulghafor Ibrahim Abdullah

\begin{tabular}{|c|c|c|c|c|c|c|c|}
\hline \multicolumn{8}{|c|}{$\frac{\text { Wavelength }}{1.3 \mu \mathrm{m}}$} \\
\hline NA & 0.07 & 0.12 & 0.095 & 0.158 & 0.153 & $\begin{array}{c}\text { Not } \\
\text { available }\end{array}$ & Unit less \\
\hline $\mathrm{A}_{\text {eff }}$ & 89 & 33 & 52 & 9 & 38 & $\begin{array}{c}\text { Not } \\
\text { available }\end{array}$ & $\left(\mu \mathrm{m}^{2}\right)$ \\
\hline NLC & 4 & 4.5 & 5.5 & 20 & 54 & $\begin{array}{c}\text { Not } \\
\text { available }\end{array}$ & $\mathbf{K m}^{-1} \mathbf{W}^{-1}$ \\
\hline$D(\lambda)$ & 10 & 22 & -20 & 80 & 0.0 & $\begin{array}{c}\begin{array}{c}\text { Not } \\
\text { available }\end{array} \\
\end{array}$ & Ps/nm.km \\
\hline \multicolumn{8}{|c|}{$\frac{\text { Wavelength }}{1.5 \mu \mathrm{m}}$} \\
\hline NA & 0.08 & 0.135 & 0.11 & 0.27 & 0.157 & $\begin{array}{c}\text { Not } \\
\text { available }\end{array}$ & Unit less \\
\hline $\mathrm{A}_{\text {eff }}$ & 91 & 33 & 54 & 9 & 39 & $\begin{array}{c}\text { Not } \\
\text { available }\end{array}$ & $\left(\mu \mathrm{m}^{2}\right)$ \\
\hline NLC & 3 & 4 & 3.5 & 10 & 53 & $\begin{array}{c}\text { Not } \\
\text { available }\end{array}$ & $\mathbf{K}^{-1} \mathbf{W}^{-1}$ \\
\hline $\mathrm{D}(\lambda)$ & 10 & 77 & -30 & 100 & 0.0 & Not available & Ps/nm.km \\
\hline
\end{tabular}

\section{4- Conclusions}

The wavelength dependence of the fiber parameters $\mathrm{NA}(\lambda), \mathrm{A}_{\mathrm{eff}}(\lambda)$ and $\gamma(\lambda), D(\lambda)$, and $d \mathrm{D}(\lambda) / \mathrm{d} \lambda$ for the proposed structures are taken into account. For large pitch size PCF, the increasing of air hole radius has a significant effect on the PCF parameters; pushed the $\lambda_{\text {ZD }}$ toward the shorter wavelength. The proposed PCF3 of $\mathrm{r}=1.0 \mu \mathrm{m}$ exhibits zero dispersion, lowest dispersion slope and largest nonlinear coefficient at a range of wavelength including the important communication windows. All the proposed structures shows large negative dispersion at $\lambda=0.8 \mu \mathrm{m}$ of Ti-Za laser. By selecting the appropriate combination of air hole size, pitch size, and number of the rings one can design PCFs with specific properties. This will be the future work.

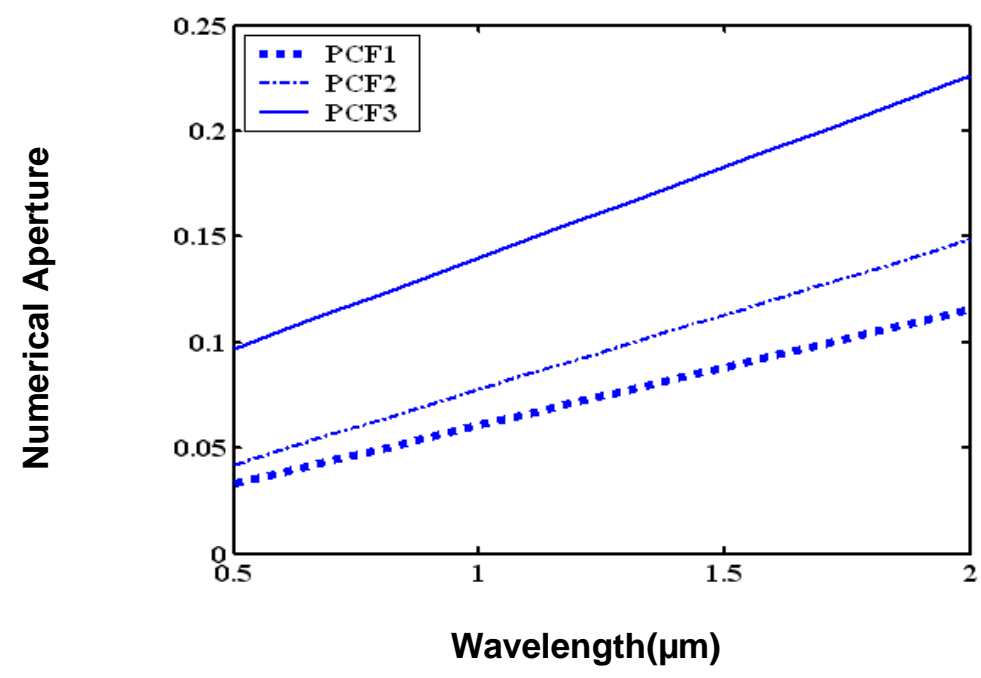

Fig.4: Numerical aperture $v s$ wavelength for proposed PCFs.
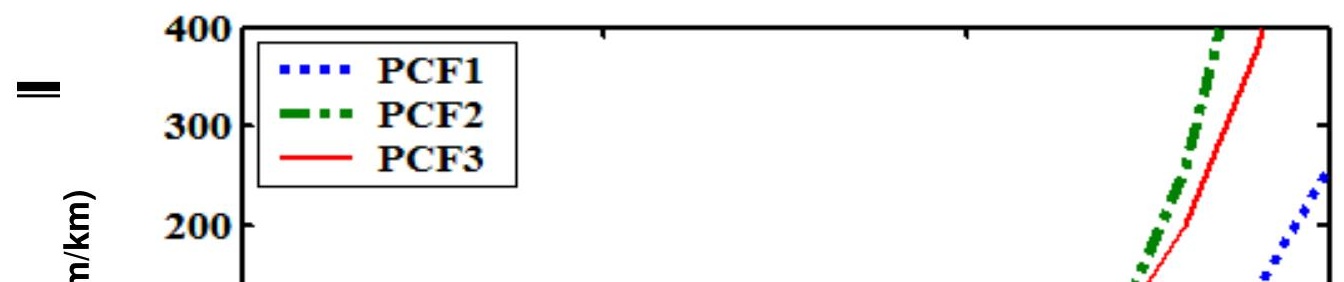


\section{A}

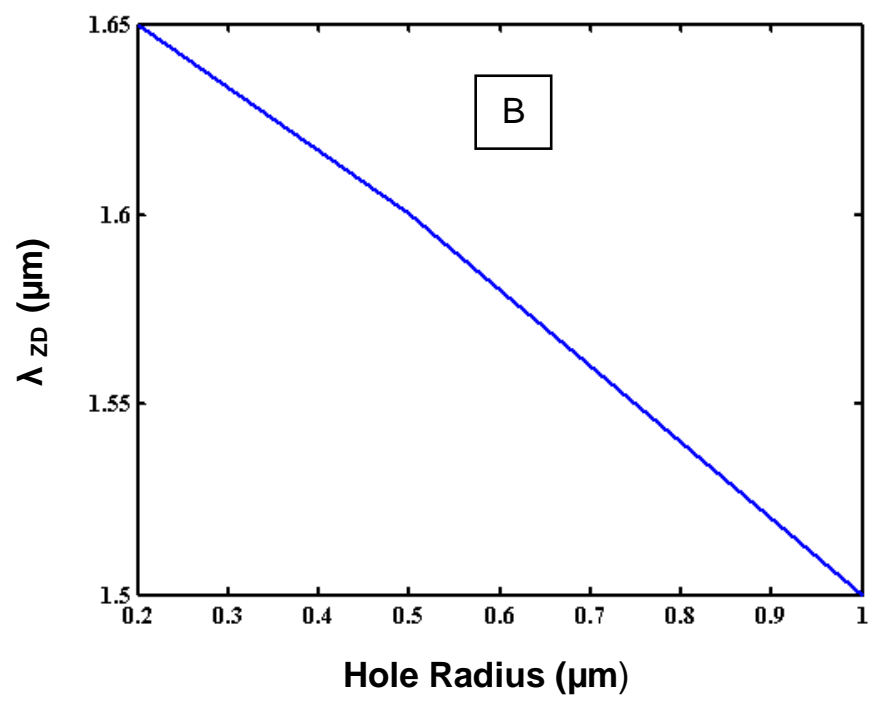

Fig. 5: A-Dispersion computed vs wavelength for proposed PCFs. B- Zero dispersion wavelength $\lambda_{\mathrm{ZD}} v s$. air hole radius. 


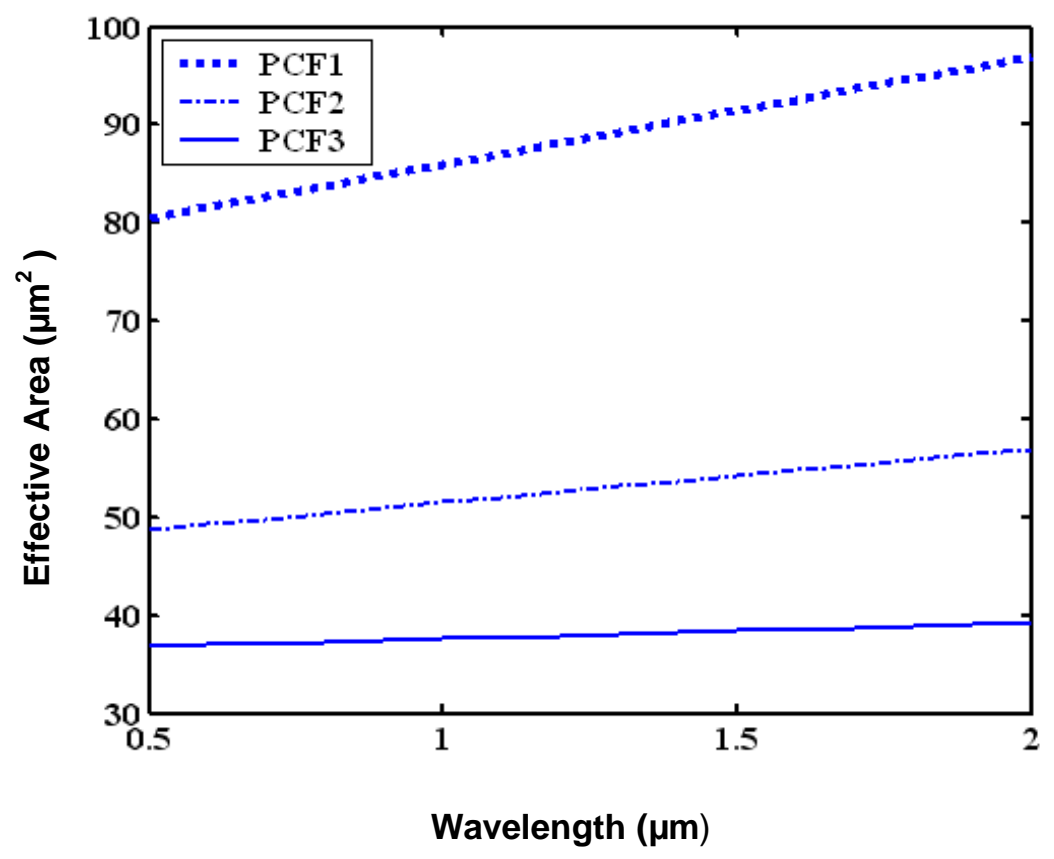

Fig.6: Effective area $v s$ wavelength for proposed PCFs.

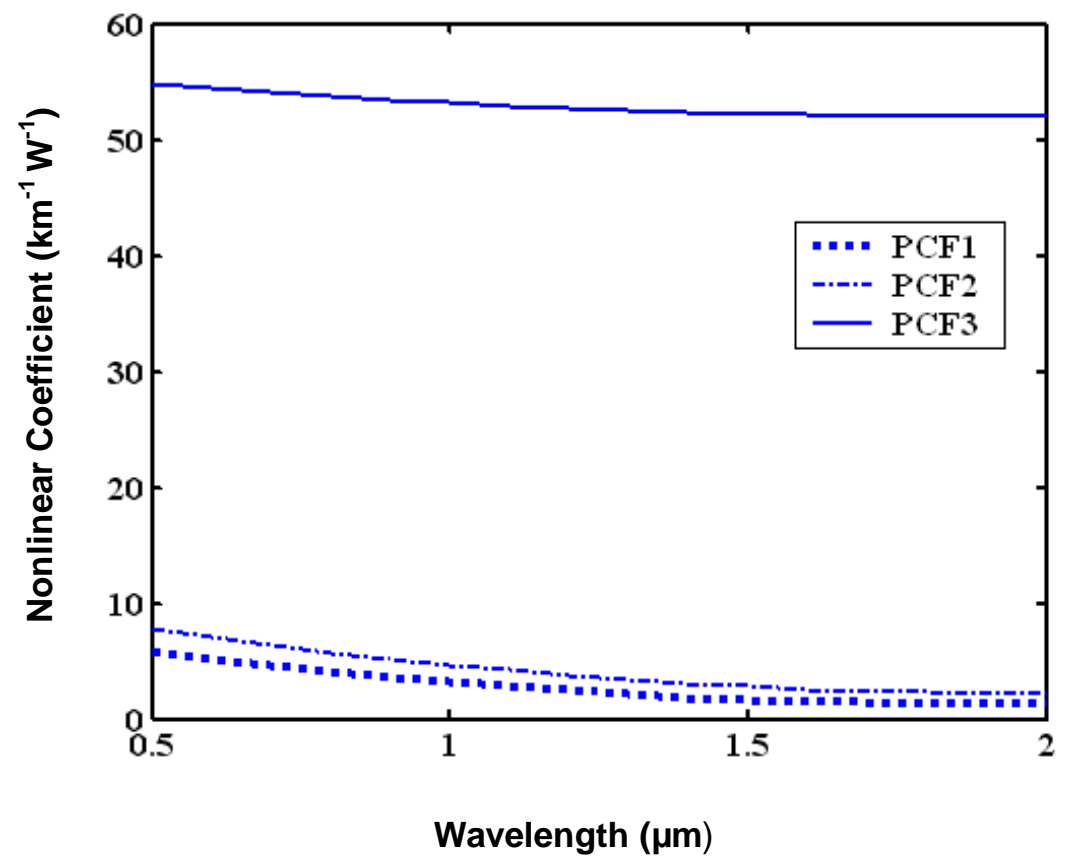

Fig. 7: Nonlinear linear coefficient $v s$ wavelength for proposed PCFs. 


\section{5- References}

1) Knight J. C., Birks T. A., Russell P. St. J., and Atkin D. M., Opt. Lett., 21:1547-1549 (1997).

2) Wong K. L. G., M.Sc. Thesis, University of Auckland (2003).

3) Buck J. A., "Fundamentals of optical fibers", $2^{\text {nd }}$ Ed. John Wiley \& Sons. Inc., Hoboken New Jersey (2004).

4) Benabid F., Philosophical Transactions of the Royal Society A, 1-24 (2006).

5) Knight J. C., Broeng J., Birks T. A., and Russell P. St. J., Science 282:1476- 1478 (1998).

6) $\mathrm{Wu}$ T. L., and Chao C. H., J. of Light wave Tech. IEEE, 23:20552061 (2005).

7) Wei C., Jinyan L., Shiyu L., Haiqing L., Zuowen J and Jinggang P., Chin. Opt. Lett., Vol.5 No.7 383-384 (2007).

8) Saitoh K., Koshiba M., Hasegawa T. and Sasaoka E., Opt. Exp., 11:843-852 (2003).

9) Mortensen N. A., Opt. Exp., 10:341-348 (2002).

10) Mortensen N. A., Folkenberg J. R., Skovgaard P. M.W. and Broeng J. IEEE Photonic Technology Letters: http://arxiv.org/abs/physics/0202073 (2002).

11) Kawanishi, S., Yamamoto T., Kubota, H., Tanaka M. and Yamaguchi S. I., Mat. Res. Soc. Symp. Proc., 7969 (W7.2.1- W7.2.11) (2004).

12) Hilligsoe K. M., Progress report for Ph.D student, Dept. of Phys. And Astronomy, University. of Aarhus and NKT Academy (2003).

13) Zhu Z. and Brown T. G. Opt. Exp., 8:547-554 (2001).

14) Agrawal G.P., Nonlinear Fiber Optics, $3^{\text {rd }}$. Academic press, San Diago, CA, (2001).

15) $\mathrm{Yu}$ C. P., and H.C.. "Research on photonic crystal fibers using finite difference electromagnetic analysis"f86025@ew.ee.ntu.edu.tw.

16) Kuhlmey B. T., White T. P., Renversez G., Maystre D. Botten L.C. C. Sterek M. and McPhedran R. C., J. Opt. Soc. Am.B.19:2331-2340 (2002).

17) Reichenbach K. L., and Xu C., Opt. Exp.,Vol.13, 2799-2807 (2005).

18) He L., Yang B., Zhang X., and Yu L., Chin. Opt. Lett., Vol.4, 12, 715717(2006).

19) Saitoh K., Florous, N. and Koshiba, M., Opt. Exp.,13:21- 26 (2005). 
20) Mohamad H. M., and Abdullah A. I., "The influence of hole radius on the properties of photonic crystal fiber" accepted for publishing in J. Edu. \& Sci., College of Education, Mosul University (2007). 